\title{
Size-Dependence of Surface Plasmon Resonance and Oxidation for Pd Nanocubes Synthesized via a Seed Etching Process
}

\author{
Yujie Xiong, ${ }^{\dagger}$ Jingyi Chen, ${ }^{\dagger}$ Benjamin Wiley, ${ }^{*}$ and Younan Xia ${ }^{*}, \dagger$ \\ ${ }^{\dagger}$ Department of Chemistry \\ ${ }^{\circ}$ Department of Chemical Engineering \\ University of Washington, Seattle, Washington 98195 \\ *Corresponding author. E-mail: xia@chem.washington.edu
}

\begin{abstract}
Yadong Yin
The Molecular Foundry

Lawrence Berkeley National Laboratory, Berkeley, California 94720
\end{abstract}

\section{Zhi-Yuan Li}

Laboratory of Optical Physics, Institute of Physics

Chinese Academy of Sciences, Beijing 100080, P. R. China 


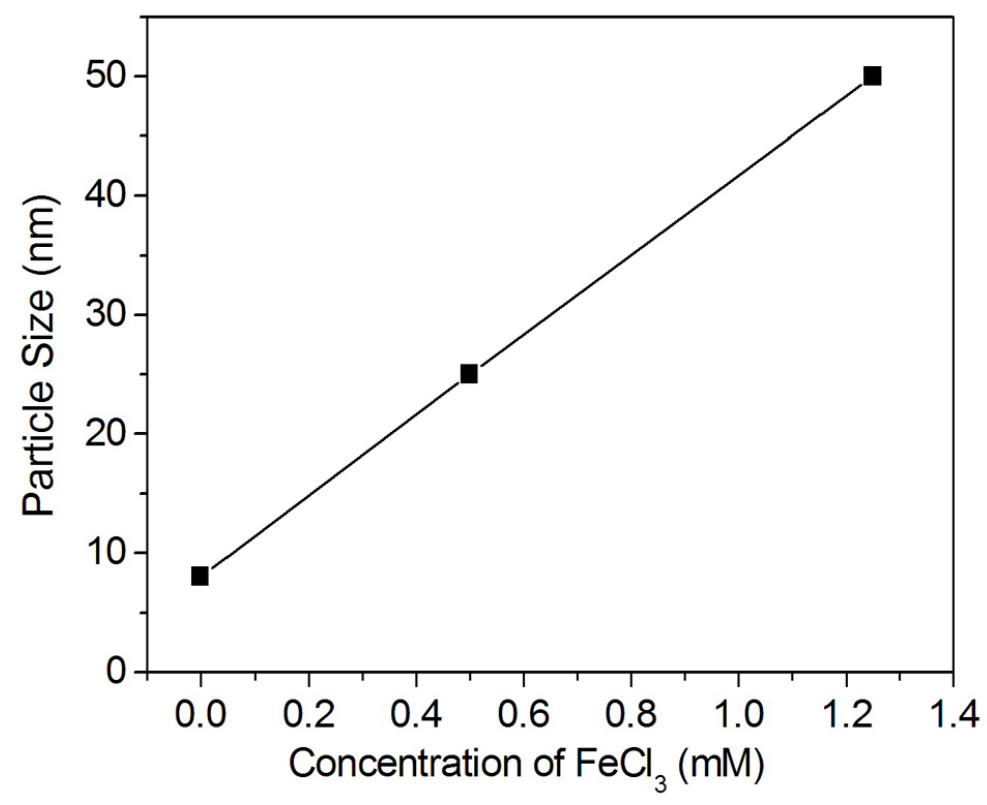

Figure S1. Dependence of cube dimension (edge length) on the concentration of $\mathrm{FeCl}_{3}$ added in the nucleation step. 


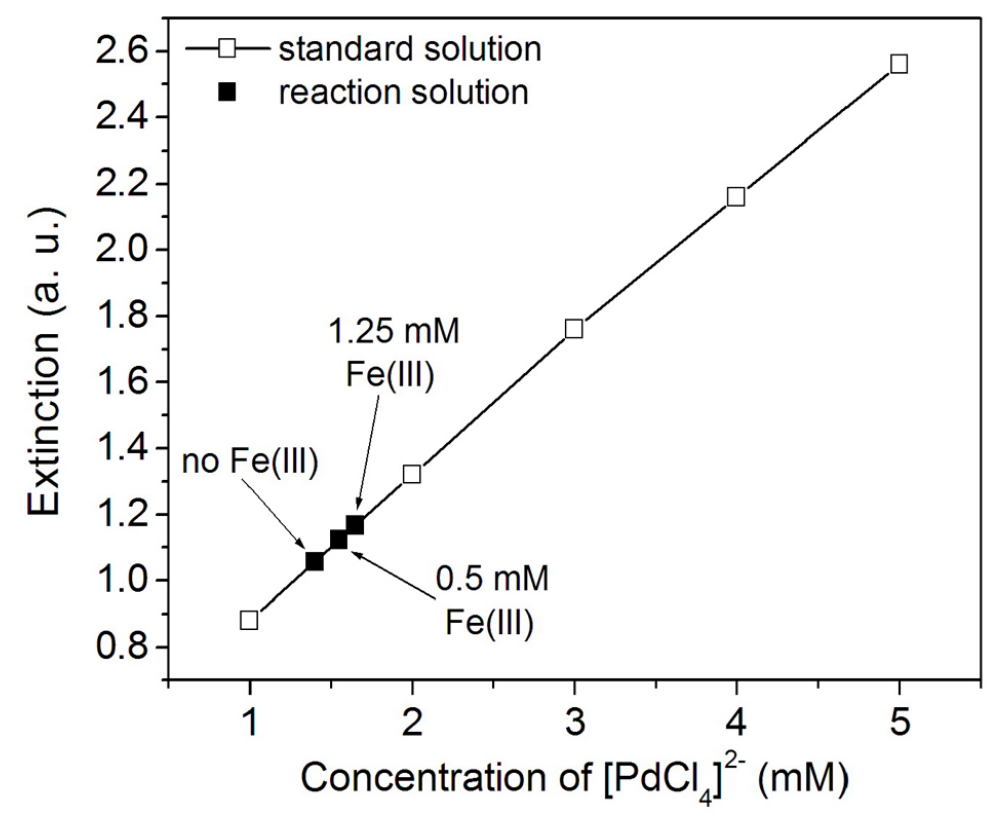

Figure S2. The concentration of $\left[\mathrm{PdCl}_{4}\right]^{2-}$ remaining in reaction solutions after particle formation was measured by comparing the peak height at $\sim 327 \mathrm{~nm}$ in the UV-vis extinction spectra to standard samples of known concentration. From these concentrations, the conversion of $\left[\mathrm{PdCl}_{4}\right]^{2-}$ into $\mathrm{Pd}$ atoms without $\mathrm{FeCl}_{3}$, and in the presence of $0.5 \mathrm{mM} \mathrm{FeCl}_{3}$ and $1.25 \mathrm{mM}$ $\mathrm{FeCl}_{3}$ was calculated to be $72 \%, 69 \%$, and $67 \%$ respectively. With Pd sizes of $8 \mathrm{~nm}, 25 \mathrm{~nm}$ and $50 \mathrm{~nm}$ corresponding to each of these conversions, the seed density was estimated to be $8.9 \times 10^{16}$ $\mathrm{L}^{-1}, 2.8 \times 10^{15} \mathrm{~L}^{-1}$, and $3.4 \times 10^{14} \mathrm{~L}^{-1}$, respectively. 

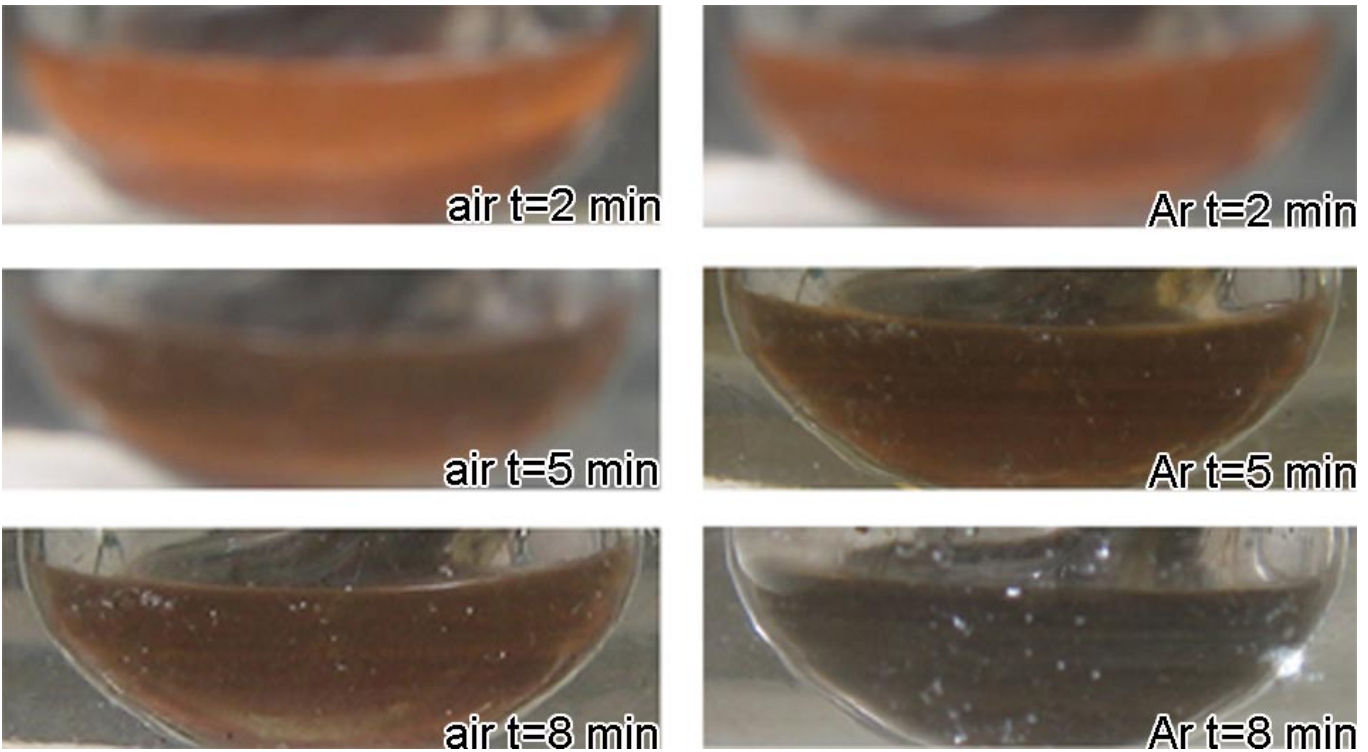

Figure S3. Photographs of a reaction performed in the presence of $1.25 \mathrm{mM} \mathrm{FeCl}_{3}$ and in air or under argon, respectively. The orange-red corresponds to the color of $\mathrm{Na}_{2} \mathrm{PdCl}_{4}$ solution while the brown/black color indicates the formation of Pd nanoparticles. Without oxygen, the concentration of $\mathrm{Fe}$ (III) in the solution should quickly decrease as ethylene glycol reduces $\mathrm{Fe}$ (III) to $\mathrm{Fe}$ (II). Because $\mathrm{Fe}$ (II) cannot oxidize palladium, the seeds could not be etched. As shown by the color change with time, when the reaction was performed with continuous bubbling of argon, Fe(III) retarded nucleation only within the first 2 minutes, after which nucleation accelerated. 


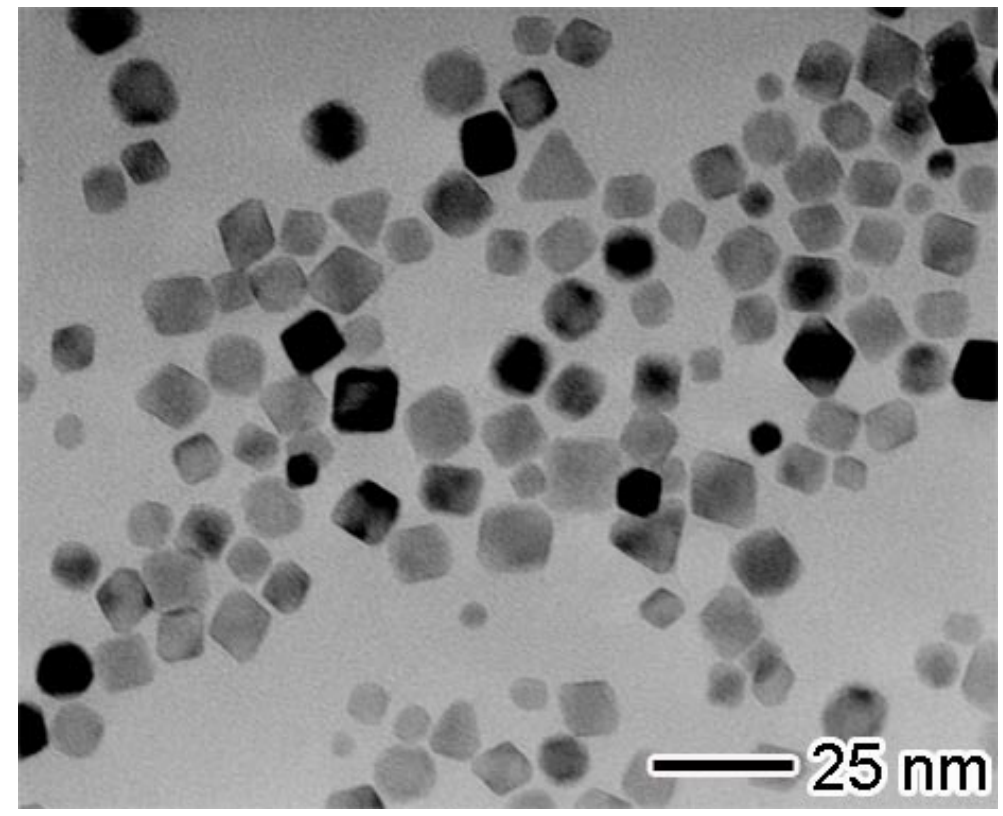

Figure S4. TEM image of 10-nm Pd nanocubes obtained under argon in the presence of 1.25 $\mathrm{mM} \mathrm{FeCl}_{3}$ at $\mathrm{t}=3 \mathrm{~h}$. When the reaction was performed with continuous bubbling of argon, $\mathrm{Fe}$ (III) retarded nucleation only within the first 2 minutes, after which nucleation accelerated. The final product mainly contained Pd nanocubes of $\sim 10 \mathrm{~nm}$ in size, because the number of seeds was only reduced by a small fraction. 


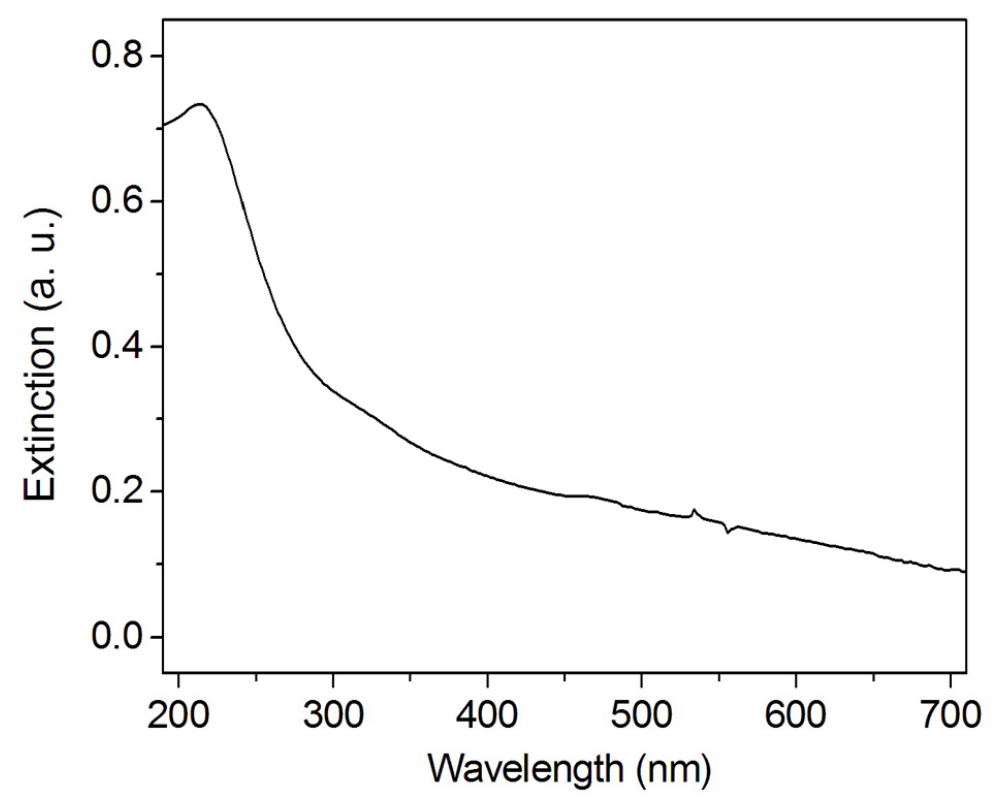

Figure S5. UV-vis spectrum of Pd nanocubes with an average size of $8 \mathrm{~nm}$. As calculated using the DDA method or Mie theory (Creighton, J. A.; Eadon, D. G. J. Chem. Soc. Faraday Trans. 1991, 87, 3881), the resonance peak of such a small Pd nanocube is located at $\sim 225 \mathrm{~nm}$. The measured spectrum shows an extinction peak covering 200-240 nm. Note that there is a small amount of PVP on the surface of as-prepared Pd nanocubes, and the absorption peak of PVP is at 212 nm (Chen, J.; Herricks, T.; Geissler, M.; Xia, Y. J. Am. Chem. Soc. 2004, 126, 10854; Xiong, Y.; Chen, J.; Wiley, B.; Xia, Y.; Aloni, S.; Yin, Y. J. Am. Chem. Soc. 2005, 127, 7332). Therefore, the detected signal peak should be convolution of the resonance peak of 8-nm Pd nanocubes and the absorption peak of PVP. 